\title{
O agronegócio cafeeiro no município de Guaranésia-MG
}

\author{
The coffee agribusiness in the municipality of Guaranésia-MG
}

\author{
Renata Vieira de Melo \\ Mestranda em Geografia - UNIFAL, Brasil \\ renata.vieirademelo78@gmail.com
}

\begin{abstract}
Resumo
O Brasil é um dos principais países exportadores de café, sendo a mesorregião sul/sudoeste de Minas Gerais a principal região produtora deste agronegócio. A consolidação e expansão da cafeicultura na região destaca a dependência econômica da atividade na mesorregião, tanto para a dinâmica urbana quanto agrária, tendo em vista a grande participação de minifúndios e pequenas propriedades como base da produção. Assim, a monocultura do café nesta região mineira se diferencia das regiões onde o agronegócio se destaca pelas grandes propriedades, sendo sua organização agrária um híbrido entre pequenas e grandes propriedades. Nesse presente artigo, coloca-se a questão de compreender a produção do agronegócio cafeeiro sul mineiro, onde, de um lado possuí altos investimentos em capital, através de grandes empresas que viabilizam a produção, e de outro, trata-se de um agronegócio produzido, em grande maioria, pelos produtores familiares. Com intuito de analisar as relações dos principais agentes envolvidos na produção desta agricultura desta região, destaca-se a produção cafeeira do município de Guaranésia, estando este entre os municípios produtores do país, pois, acredita-se que possa elucidar a realidade da região. Para tanto, se realizou um estudo com a temática das relações campo-cidade, por confiar que há nela elementos teórico-conceituais capazes de auxiliar na investigação empírica. Dessa forma, este artigo tem por objetivo compreender a dinâmica da produção cafeeira no município de Guaranésia, através dos principais agentes envolvidos na mesma.
\end{abstract}

Palavras-chave: Café, Agronegócio, Agricultura, Agrária.

\begin{abstract}
Brazil is one of the leading coffee exporting countries, the southern/south-western mesoregion of Minas Gerais being the main producing region of this agribusiness. The consolidation and expansion of coffee production in the region highlight the economic dependence of the activity in the mesoregion, both for urban and agrarian dynamics, given the significant participation of small farms as the production base. Thus, the monoculture of coffee in this region of Minas Gerais differs from the regions where agribusiness stands out for its extensive properties, and its agrarian organisation is a hybrid between small and large farms. Here, the question arises of understanding the production of the coffee agribusiness in the south of Minas Gerais, where, on the one hand, it has high capital investments, through large companies that enable production, and on the other, it is an agribusiness produced in a vast majority, by family producers. In order to analyze the relationships of the leading agents involved in the production of this region's agriculture, we intend to investigate the coffee production of the municipality of Guaranésia, being this one of the largest producers in the country in the last harvests, since it believed that it could elucidate the reality of the region. Therefore, it proposed to carry out a study with the subject of the field-city relations, because we trust that there are theoretical-conceptual elements capable of assisting the empirical investigation. Thus, this research aims to understand the dynamics of coffee production in the municipality of Guaranésia, through the main agents involved in it.
\end{abstract}

Keywords: Coffee, Agribusiness, Agriculture, Agrarian. 


\section{INTRODUÇÃO}

Mundialmente e historicamente conhecido pelo seu café, o Brasil se destaca no cenário econômico mundial como um dos principais países exportadores. Nesse contexto é de fundamental importância ressaltar que a mesorregião sul/sudoeste de Minas Gerais destaca-se como a principal região produtora deste agronegócio. Referido acompanhamento da CONAB (Companhia Nacional de Abastecimento) demonstra ainda que o maior estado produtor de café do País - Minas Gerais participou com $54,3 \%$ da produção nacional em 2017 , pois obteve um volume corresponde a 24,45 milhões de sacas e de acordo com a ABIC (ASSOCIAÇÃO BRASILEIRA DA INDÚSTRIA DO CAFÉ) Minas Gerais participou com 54,3\% da produção nacional de café, seguida pelo Espírito Santo com 19,7\%, São Paulo - 9,8\%, Bahia - 7,5\%, Rondônia-4,3\% e Paraná com 2,7\%.

A consolidação e expansão da cafeicultura na região evidencia a dependência econômica da atividade na mesorregião, tanto para a dinâmica urbana quanto agrária, tendo em vista a grande participação de minifúndios e pequenas propriedades como base da produção. De acordo com o IBGE (Instituto Brasileiro de Geografia e Estatística) grande parte do produto sai de pequenas propriedades de agricultura familiar (79\% do total de produtores em Minas, segundo o último Censo) - que utilizam processos semi-mecanizados de produção - com destino à exportação, conquistando mercados principalmente nos EUA, Europa e Japão.

Assim, a monocultura do café nesta região mineira se diferencia das regiões onde o agronegócio se destaca pelas grandes propriedades, sendo sua organização agrária um híbrido entre pequenas e grandes propriedades. Aqui, coloca-se a questão de compreender a produção do agronegócio cafeeiro sul mineiro, onde, de um lado possuí altos investimentos em capital, através de grandes empresas que viabilizam a produção, e de outro, trata- se de um agronegócio produzido, em grande maioria, pelos produtores familiares.

Esta reflexão justifica-se pelo o intuito de analisar as relações dos principais agentes envolvidos na produção do café desta região e a produção cafeeira do município de Guaranésia MG, estando este entre os municípios produtores do país, pois se acredita que possa elucidar e trazer contribuições para a compreensão à cerca realidade da região. Ao destacar este fato, o que se quer salientar, é a seguinte questão: como ocorrem as inter-relações dos principais agentes envolvidos na cafeicultura desta região? Entendendo como principais agentes o cafeicultor (familiar e não familiar),o Estado (principalmente através de políticas públicas que favoreçam a instalação de grandes grupos empresariais e a atuação com programas de financiamentos de créditos), as empresas de café (grupos instalados na região que atuam no setor cafeeiro, desde as atividades inerentes à produção, passando pelo beneficiamento e transformação do grão, até a normatização e regulamentação para a exportação) e nesse contexto analisar ainda às relações de trabalho (formal e 
informal) empregadas nesse agronegócio a fim de esclarecer as alterações pelas quais passaram as relações laborais na cafeicultura diante a reprodução do capital na fase de mundialização em que há graves e sucessivas denúncias trabalho degradante na atividade cafeeira associada ao aspecto da escravidão contemporânea.

\section{METODOLOGIA}

\subsection{Teórica}

Para que seja mantida linha de raciocínio com coesão epistemológica e melhor sistematização dos resultados encontrados, pretendeu-se adotar uma abordagem teóricametodológica coerente, nesse sentido, os conceitos que norteiam a discussão da pesquisa são relacionados com as seguintes leituras: i) formação econômica do Brasil (PRADO JR., 2008); ii) constituição do moderno, transição feudalismo- capitalismo (MARX, 1988); iii) cidades funcionais ao campo moderno (cidades do agronegócio) (SANTOS 1994; ELIAS, 2011); e iv) globalização e neoliberalismo (CHESNAIS, 1996; HARVEY, 2008).

Acredita-se que este referencial teórico seja capaz de embasar a compreensão do objeto empírico que se propõe nesta pesquisa, ou seja, a análise das relações campo-cidade a partir da produção cafeeira no município de Guaranésia - MG.

\subsection{Temática}

Paralela à leitura dos conceitos teóricos também se fez necessário à revisão bibliográfica temática, cujo objetivo principal centra-se nas leituras sobre assuntos mais específicos da produção cafeeira e na análise das relações campo-cidade. Desta maneira, a leitura será amparada em livros, artigos e periódicos que tratam sobre os seguintes temas: i) cafeicultura no estado de Minas Gerais (ANDRADE 1994; SAES et al, 2010); ii) modernização agrícola (MÜLLER, 1989; MAZZALI, 2000); iii) - relação campo- cidade (ELIAS, 2007; SOROKIN et al 1981; RUA, 2005; LEFEBVRE, 1999; CARLOS, 2004; ALENTEJANO, 2003).

\subsection{Levantamentos de dados primários}

Como embasamento metodológico para a obtenção dos dados primários, foi utilizado o texto de Denise Elias (2007), que, em síntese, traz a abordagem metodológica para identificação de municípios que são funcionais à produção do campo (cidades do agronegócio).

Destaca-se a relevância de consultas em diversos órgãos, entidades, institutos de pesquisas e banco de dados, entre outros, que permitem nortear o pesquisador. Por entender que para alcance 
do objetivo final, esta pesquisa perpassa pela caracterização do município mediante sua produção cafeeira, foi adotado como base de buscas o texto acima referido, além disso, fez-se necessário: realizar pesquisa sobre a produção cafeeira (quantidade produzida, área e valor da produção) em Guaranésia - MG nos últimos anos; e a consulta dados atuais da estrutura fundiária da mesorregião sul/sudoeste de Minas Gerais; visando articular a produção cafeeira como elemento constituinte da realidade local.

Realizou-se também o levantamento dos eventos culturais e/ou econômicos específicos inerentes à produção agrícola do município, em especial à cafeicultura; assim como estabelecimentos de produção e comercialização do café (cooperativas, armazéns, torrefadoras, empresas de comércio e exportação revendedoras de insumos e maquinários agrícolas, institutos de pesquisas agrícolas, bancos e demais agências de financiamentos de crédito, etc.); fez-se também o levantamento dos principais projetos e programas governamentais, a partir de 1960, que favoreceram a instalação de grandes grupos empresariais na região cafeicultora do Sul de Minas.

Para a fundamentação quantitativa foi realizado um levantamento de dados secundários que servirá para comprovação de hipóteses e aquisição de informações importantes para esclarecer a problemática de nosso objeto de estudo. Para tal, a coleta compreenderá os seguintes dados: 1) quantidade produzida, valor da produção, área da produção de café em Guaranésia - MG, objetivando verificar e/ou comprovar que Guaranésia está entre os principais municípios produtores de café; 2) Produto Interno Bruto (PIB) do município de Guaranésia, por setor de atividade (indústria, serviços e comércio), a fim de verificar a dependência econômica de Guaranésia à produção cafeeira, correlacionando os dados da produção cafeeira ao setor agropecuário do PIB municipal, e a quantidade de empresas locais aos setores indústria e serviços do PIB municipal; 3) estrutura fundiária do município de Guaranésia, relação percentual dos estabelecimentos agropecuários em pequenos, médios e grandes, com o intuito de verificar a origem (propriedades produtoras) da produção cafeeira, ou seja, identificar a quantidade proveniente da agricultura familiar e não familiar; 4) Censo demográfico de Guaranésia, objetivando identificar o crescimento populacional e, assim, constatar se houve migração para o município devido à cafeicultura; 5) tipos de vínculos empregatícios dos trabalhadores de Guaranésia, a fim de verificar se a produção cafeeira gera empregos para a cidade.

A princípio foram utilizadas para a obtenção dos dados acima mencionados as seguintes fontes: Instituto Brasileiro de Geografia e Estatística (IBGE / Produção Agrícola Municipal - PAM) /Sistema de Recuperação de Dados do IBGE - SIDRA); Secretaria de Estado de Agricultura, Pecuária e Abastecimento de Minas Gerais (SEAPA-MG); Anuário Estatístico do Café (Gazeta Mercantil); Cecafé (Confederação dos Exportadores de Café); ABIC (Associação Brasileira da 
Indústria de Café); Relação Anual de Informações Sociais (RAIS) / Cadastro Geral de Empregados e Desempregados (CAGED) no Ministério do Emprego e Trabalho.

\subsection{Caracterização da área de estudo}

De acordo com a delimitação do IBGE, a Mesorregião Sul/Sudoeste de Minas Gerais, que trataremos neste artigo como MSS-MG, é composta por 10 Microrregiões e 146 municípios, dentre eles o município de Guaranésia.

Guaranésia é um município brasileiro do Estado de Minas Gerais (maior produtor de café do país) que faz parte da mesorregião do sul/sudoeste de MG e da microrregião de São Sebastião do Paraíso. Sua população estimada em 2018 era de 19.025 habitantes e seu PIB foi em 2016 o valor correspondente a 37.357.577.000 reais, sendo boa parte destes referentes a atividades agrícolas.

A área do município corresponde a $294 \mathrm{~km}^{2}$ possuindo densidade demográfica de 65,91 hab./ $\mathrm{km}^{2}$. Este município se caracteriza pelas culturas agrícolas do café, milho e cana, sendo o café uma das produções mais expressivas. No município é possível identificar também um parque industrial com fábricas de tecidos, de massas alimentícias, de cabines para máquinas de construção e agrícolas, para locomotivas e conjuntos soldados. Em relação a agropecuária destaca-se a pecuária bovina, suína e a produção de aves de corte.

Centrado na produção cafeeira de acordo com a Pesquisa Agrícola Municipal (PAM) o município possui 3435 hectares de área plantada de café e produziu 4675 toneladas de café no ano de 2017.

As atividades turísticas voltadas a agricultura também são evidentes entre os 51 circuitos turísticos de Minas, criados pela Secretaria de Estado de Turismo para caracterizar e disciplinar a atividade turística por meio de características próprias de cada setor, está o Circuito Montanhas Cafeeiras, que reúne 12 municípios da região Sul, em que a produção de café é o principal produto econômico, mas onde há outros atrativos naturais, e o município de Guaranésia junto com outros 11 municípios faz parte deste circuito.

Aproveitando que o setor cafeeiro é expressivo no município há a realização de eventos voltados a essa atividade agrícola como o Circuito Mineiro de Cafeicultura do Sul de Minas que o município sediou no ano de 2018. O evento foi destinado aos produtores do programa Agricultura Familiar, que teve como objetivo melhorar a qualidade do café, redução de custos na produção e manejo e consequentemente aumentar os ganhos na comercialização do produto.

Desta forma Guaranésia-MG está inserida no contexto das cidades do agronegócio sendo de fundamental importância para o desenvolvimento econômico e cultural do Estado de Minas Gerais. Assim como, colabora na historicidade do Estado junto com os municípios da federação. 


\section{REFERENCIAL TEÓRICO}

Como pressuposto de categoria de análise, objetivando orientar a reflexão supracitada, acredita-se que a análise espacial permita exame que envolva todos os agentes, ao considerar, segundo SANTOS (1996a, p.51), que o espaço é "um conjunto indissociável, solidário e também contraditório, de sistemas de objetos e de sistemas de ações, não considerados isoladamente, mas como o quadro único no qual a história se dá" e, acrescentando-se ainda, uma compreensão do espaço não como palco, mas como meio, condição e produto da sociedade, sendo o espaço pressuposto para a produção capitalista (CARLOS apud ANSELMO, 2005).

No concernente ao sistema econômico da sociedade hodierna, referente à produção da agricultura, que é o objeto empírico deste estudo, Oliveira (2002) esclarece que ocorrem duas formas de reprodução do capital no campo, sendo elas, a territorialização e a monopolização do capital. A primeira se refere a um mecanismo especificamente capitalista, em que o capitalista se torna também proprietário de terra. Dessa forma, ocorre uma apropriação (pelo capitalista/proprietário) simultânea do lucro da atividade industrial e da agrícola, como também da renda da terra originada por esta atividade agrícola. Sendo exemplo emblemático desta situação os centros produtores de cana-de-açúcar, soja, laranja, pastagem e café. A monopolização do território é uma maneira que o capital monopolista encontrou para se reproduzir através de formas não capitalistas de produção, redefinindo as relações de produção, na qual o próprio capital cria as condições para o campo produzir as matérias-primas para as indústrias capitalistas.

Nesse sentido, o embasamento sobre a temática das relações campo-cidade foi realizado com base em Alfredo (2008), que considera a divisão agrário-urbana como pressuposto para compreender a constituição do moderno e, com isso, da modernização do Brasil, fator relevante que auxilia na compreensão da peculiaridade da produção de uma monocultura de exportação produzida por agricultores familiares.

Foi durante o século XX que a MSS-MG se consolidou como a principal região cafeeira do país, a partir da expansão espacial da cultura dos estados de São Paulo e Paraná (que eram os principais estados cafeicultores), para Minas Gerais. Acerca deste processo histórico, segundo a pesquisa de ANDRADE (1994), Minas Gerais aglomerou numerosas vantagens para se tornar, a partir dos anos de 1980 e ainda hoje, o principal estado produtor de café:

Do ponto de vista de Minas Gerais, este estado recebeu o café com todo o apoio governamental, beneficiando-se ainda da presença do IBC [Instituto Brasileiro do café] nos anos setenta e oitenta, antes que esta autarquia entrasse num processo acelerado de decadência. Beneficiando-se também do apogeu da política de crédito agrícola nos anos setenta. Avançou em termos de produtividade, e deslocou-se para outras regiões do Estado. Minas Gerais representa, assim, a região onde uma nova forma de produzir o café se instala: a princípio com recursos financeiros abundantes (ANDRADE, 1994, p. 3) 
Tratando-se de uma região cuja economia era incipiente, o autor (ANDRADE,1994) esclarece que o apoio governamental (concessão de créditos e políticas públicas regionais) somado a outros Programas Governamentais (Programa de Renovação e Revigoramento dos Cafezais PRRC, por exemplo), favoreceu a implantação de uma "nova forma de produzir o café", ou seja, com muitos recursos em capital.

Como foi o caso do Sul de Minas, que reativou em outras bases sua atividade cafeeira. Até então a cafeicultura era explorada de forma arcaica e com baixa produtividade, mas os créditos financeiros desse Programa [PRRC] provocaram mudanças radicais na forma de se explorar o café (ANDRADE, 1994).

Nota-se, dessa forma, que os recursos creditícios e político-institucionais foram os fatores fundamentais para a realização da produção cafeeira na região. Assim, ao observar no território a presença de grandes grupos empresariais que se instalaram a partir de Programas Governamentais e incentivos fiscais, percebe-se que o capital encontrou vantagens para sua territorialização. Da mesma maneira, analisar o processo histórico-econômico da região, que a princípio era produtora de vários alimentos para o abastecimento, ou seja, agricultura familiar, ao se deparar atualmente com pequenas e médias indústrias nas pequenas propriedades, fica evidente o processo de monopolização do capital, segundo as concepções de Oliveira (2002).

O processo de modernização da agricultura ocorreu concomitante ao processo da Revolução Verde, que segundo Brum (1987):

Revolução Verde foi um programa que tinha como objetivo explícito contribuir para o aumento da produção e da produtividade agrícola no mundo, através do desenvolvimento de experiências no campo da genética vegetal para a criação e multiplicação de sementes adequadas às condições dos diferentes solos e climas e resistentes às doenças e pragas, bem como da descoberta e aplicação de técnicas agrícolas ou tratos culturais mais modernos e eficientes (BRUM, 1987, p.44).

O Complexo Agroindustrial no entendimento de Müller (1989, p.23) "é uma forma de unificação das relações interdepartamentais com os ciclos econômicos e as esferas da produção, distribuição e consumo, relações essas associadas às atividades agrárias.

Ainda, corroborando com esta afirmativa sobre as interações da agricultura com a indústria, Mazzali (2000), define Complexo Agroindustrial: “(...), trata-se da articulação da agricultura, por um lado, com a indústria produtora de insumos e bens de capital agrícolas e, por outro lado, com a indústria processadora de produtos agrícolas, a agroindústria”(MAZZALI, 2000, p. 17).

Conforme as observações supracitadas, a agricultura moderna estreitou as relações entre os espaços do campo e da cidade, uma vez que ambos atuam em uma dinâmica conjunta no processo da produção da cultura. Ainda, com apoio em Alfredo (2008), compreende-se que o estudo das relações campo-cidade é pressuposto para compreender a constituição do moderno. 
A agricultura moderna exige suportes técnicos e especializados que se fazem presentes nas cidades, estabelecendo-se desta maneira uma nova relação campo-cidade (ELIAS, 2007). Com intuito de atender às exigências da agricultura moderna, as cidades desenvolvem diversos sistemas técnicos e normativos, que as tornam funcionais às exigências produtivas do campo moderno.

A cidade torna-se o lócus da regulação do que se faz no campo. É ela que assegura a nova cooperação imposta pela nova divisão do trabalho agrícola, porque obriga a afeiçoar-se às exigências do campo, respondendo às suas demandas cada vez mais prementes e dando-lhe respostas cada vez mais imediatas. Como aponta Santos (1996), "tudo isso faz com que a cidade local deixe de ser a cidade no campo e transforme-se na cidade do campo.".

Nesse sentido, Elias (2007) denominou de cidades do agronegócio aquelas que se tornaram funcionais à produção agropecuária moderna, onde descreve quais os elementos de investigação que permitem esta classificação. Assim, a autora (idem), elenca uma série de fatores (estando o estudo 12 das relações campo-cidade entres eles), que estão direta e indiretamente relacionados à produção de um agronegócio, que permitem identificar se o município pode ser considerado como uma cidade do agronegócio.

Diante desta atual dinâmica social, espacial e econômica, que revela a interdependência entre os espaços do campo e da cidade, considera-se que os pressupostos da investigação das relações campo-cidade sejam essenciais para compreender as dinâmicas territoriais do município de Guaranésia, a partir da produção cafeeira.

De fundamental importância constatar também que para que essas relações sejam possíveis o sistema de redes são objetos responsáveis para viabilizações de processos inerentes a circulação global de mercadorias agrícolas.

Diferente da modernização agrícola das décadas de 1960 a 1980, hoje a rede de produção agroindustrial está interligada com os setores de transporte e logística, sendo os fluxos da rede no território. Há, portanto, uma especialização no interior das redes que acaba por intensificar as relações de interdependência entre as empresas e demais agentes econômicos. De acordo com Guilhon (1992), existem redes de dois tipos: as horizontais e as verticais. Nessa perspectiva, pesquisaremos sobre as verticais, pois estas: “(...), envolvem a articulação estreitas das atividades de um conjunto de fornecedores e distribuidores por uma empresa coordenadora que exerce considerável influência sobre as ações desses agentes, além de assegurar o controle estratégico de toda a cadeia (MAZZALI, 2000, p.158).

Logo, a rede vertical está vinculada a uma empresa central, que controlam todas as atividades relacionadas à cadeia produtiva. Dando continuidade a suas conclusões acerca das redes, o autor afirma: 
As redes horizontais se dão por meio de alianças entre correntes com os objetivos de assegurar o acesso a novos conhecimentos e/ou a entrada em novos mercados. Assim, enquanto a estruturação horizontal objetiva a expansão dos campos de atuação e a garantia da apropriação dos resultados do esforço de inovação, a estruturação vertical está voltada para a gestão das operações, coordenando as decisões de múltiplos agentes no interior do processo produtivo (MAZZALI, 2000, p.163).

Inserido a toda essa estrutura complexa de mundialização do capital do agronegócio ao longo do século XIX, a mesorregião sul/sudoeste de Minas se consolidou como a principal região cafeicultora do país (SAES et al, 2010). Por esse motivo, encontram-se no território desta região inúmeros grupos empresariais que atuam na produção cafeeira, estruturando, dessa maneira, uma rede para a produção do agronegócio do café. Todavia, é importante salientar que a estrutura fundiária da região é fragmentada, ou seja, divide-se em pequenos e médios estabelecimentos agropecuários, o que implica que a produção do agronegócio cafeeiro é produzida, em grande maioria, pela agricultura familiar. Este fato peculiar se transforma na problemática desta pesquisa, uma vez que há financiamentos de créditos e programas políticos diferenciados para estas produções agrícolas - a familiar e a não familiar.

Entremeado a toda essa conjuntura que reproduz a lógica do capital na produção cafeeira em Minas Gerais, não pode deixar de identificar as relações de trabalho correlatas a ela. Há especulações sobre um cenário de precarização da classe trabalhadora que está ligado de modo direto com as formas assumidas pelo capital em aumentar a produtividade do trabalho. A substituição da mão de obra humana por máquinas ocorre visando a elevação dos índices produtivos. Com essa tocante substituição de trabalhadores, viu-se necessário, pelo capital, de somar ainda mais a intensidade da produtividade daqueles que estão empregados de modo a obter maiores taxas de exploração. Elevando a produtividade, amplia- se, também, o potencial do capital de se apropriar da mais-valia, o que quer dizer que mais trabalho está sendo realizado por uma mesma ou menor quantidade de força de trabalho empregada, ou seja, diante a grande força de trabalho que se torna supérflua para o capital, os demais que conseguem se inserir no mercado de trabalho são pressionados a produzirem mais e em ritmo cada vez maior como mostrou Marx, em interpretação que se torna cada vez mais pertinente nos dias de hoje: "O sobretrabalho da parte ocupada da classe trabalhadora engrossa as fileiras de sua reserva, enquanto, inversamente, a maior pressão que a última exerce sobre a primeira obriga-a ao sobre trabalho e a subsunção aos ditames do capital"(MARX, 1984, p. 203).

Em consonância com Menezes (2007), o trabalho análogo à escravidão em pleno século XXI é a artimanha utilizada pelo capital de recriar relações laborais antigas para dinamizar a acumulação capitalista contemporânea. Já para o Ministério Público do Trabalho (MPT2010), a sua definição refere-se à reprodução de relações de trabalho forçado e obrigatório, que não garantem as condições mínimas de dignidade a um ou mais trabalhadores. 
Perante essa realidade, analisar a conjuntura em que se instituiu dinâmica da produção cafeeira na Mesorregião Sul/Sudoeste de Minas Gerais se faz de extrema importância econômica, histórica, natural e social e poderá contribuir positivamente no avanço de pesquisas futuras.

\section{RESULTADOS E DISCUSSÕES}

Segundo o Censo Agropecuário de 2017 Guaranésia apresenta uma área de estabelecimentos agropecuários de 23.691,407 hectares, desta área cerca de 3435 hectares são destinados a colheita do café contendo 563 estabelecimentos para a produção do café tipo arábica que produzem 4.675 toneladas e emprega cerca de 1.674 pessoas. De acordo com a PAM (Pesquisa Agrícola Municipal) Guaranésia apresentou em 2017 uma renda de 33.894.000.000 reais com rendimento médio de $1361 \mathrm{~kg} / \mathrm{ha}$ derivados do café produzido no município.

Conforme levantamento da Associação Brasileira da Indústria de Café - ABIC o consumo interno de café no Brasil chegou a 21 milhões de sacas, no período de novembro de 2017 a outubro de 2018 , representando um crescimento de $4,80 \%$, com relação ao período anterior, de novembro de 2016 a outubro de 2017. Esses números elevam o consumo per capita para 6,02 kg/ano de café cru e $4,82 \mathrm{~kg}$ /ano de café torrado e moído, o que mantém o Brasil como o segundo maior consumidor de café do mundo.

O consumo de café está em plena ampliação, seguindo uma tendência que se observa globalmente. O crescimento sobre o período anterior foi de 7,03\%, evidenciando que os brasileiros estão consumindo mais café. Este aumento foi sumariamente importante porque o ano foi caracterizado por uma redução da oferta do produto, motivada pela seca severa que atingiu a região produtora em 2016 e 2017, trazendo como consequência uma elevação nos preços finais. E mesmo assim o brasileiro não reduziu a compra.

Como forma de evidenciar a grande participação da agricultura familiar na composição da econômica do Estado a partir de dados obtidos pelos IBGE constata-se que a uma grande ampliação da participação familiar na colheita do café sendo essa região um híbrido entre grandes e pequenas propriedades como podemos confirmar a partir da tabela abaixo:

Tabela 1 - Produção de café na mesorregião Sul/Sudoeste de Minas no ano de 2006.

\begin{tabular}{ccccc}
\hline Categoria & $\begin{array}{c}\text { Número de } \\
\text { estabelecimentos } \\
\text { agropecuários } \\
\text { (Unidades) }\end{array}$ & $\begin{array}{c}\text { Quantidade } \\
\text { produzida } \\
\text { (Quilogramas) }\end{array}$ & $\begin{array}{c}\text { Área colhida } \\
\text { (Hectares) }\end{array}$ & $\begin{array}{c}\text { Valor da } \\
\text { produção } \\
\text { (Reais) }\end{array}$ \\
\hline Agricultura Familiar & 31.005 & 194.073 .434 & 126.558 & 864.543 .849 \\
Não Familiar & 9.837 & 417.801 .682 & 242.830 & 1.847 .259 .840 \\
TOTAL & $\mathbf{4 0 . 8 4 2}$ & $\mathbf{6 1 1 . 8 7 5 . 1 1 6}$ & $\mathbf{3 6 9 . 3 8 8}$ & $\mathbf{2 . 7 1 1 . 8 0 3 . 6 8 9}$ \\
\hline
\end{tabular}

Fonte: IBGE. 
Retratando aos estabelecimentos comerciais voltados a negociação, comercialização e venda de produtos diretamente ligados a produção cafeeira no município de Guaranésia destacamos a presença de um núcleo da Cooxupé (Cooperativa Regional de Cafeicultores em Guaxupé Ltda.). Atualmente a Cooxupé possui mais de 14 mil cooperados - 95\% deles pequenos produtores que vivem da agricultura familiar -, recebendo café produzido em mais de 200 municípios de sua área de ação, localizada nas regiões do Sul de Minas, Cerrado Mineiro e Vale do Rio Pardo (no estado de São Paulo). A Cooxupé também possui atividades diversificadas como armazéns, exportadora, projetos como torrefação própria, auxílio na produção e comercialização de outras culturas como o milho, fábrica de rações, laboratórios para análise de folhas e solos, geoprocessamento, produtos cosméticos que utilizam como elemento de base o café entre outros investimentos. Além disso, a cooperativa vem, ao longo dos anos, ampliando seus negócios com o incentivo a produção de cafés especiais e certificados.

Atualmente, 49 países recebem o café produzido pelos mais de 13 mil cooperados da Cooxupé a maioria destes produtores são agricultores familiar e pequenos produtores, e têm se empenhado na produção um café cada vez mais sustentável, respeitando certificações e normas internacionais. A Cooxupé tem se destacado na exportação de café no país, liderando o ranking $\mathrm{n}$ desde 2008. Neste último ano foram embarcadas mais de 4 milhões de sacas de café arábica para o mercado internacional. A cooperativa realiza eventos como: workshops, treinamento, cursos e a FEMAGRI (Feira de máquinas e implementos agrícolas) onde seus cooperados podem realizar a compra de máquinas e implementos agrícolas que serão quitados nas mais diversas formas de parcelamentos baseado na troca da máquina e/ou implemento pelo produto colhido na próxima safra.

Em Guaranésia encontramos também a Talben Café Participações Agrícolas, centro dedicado a negociação e comercialização do produto na região.

Os centros de concessão de crédito também estão presentes no município destaca-se a Sicoob Credinter banco que concede financiamento para produção, custeio e compra de implementos agrícolas, atendendo da agricultura familiar à empresarial. As linhas de crédito vão da comercialização, custeio até investimento para seus associados, tais linhas originam-se de repasse e recursos próprios, do BNDES (Banco Nacional de Desenvolvimento Econômico e Social) ou do Fundo Constitucional do Centro Oeste por programas como Funcafé (Fundo de Defesa da Economia Cafeeira), Pronaf (Programa de Fortalecimento da Agricultura Familiar), e Pronamp (Programa de Apoio ao Médio Produtor Rural).

O Sumário Executivo do Café, da Secretaria de Política Agrícola - SPA, do Ministério da Agricultura Pecuária e Abastecimento - Mapa, referente ao mês de outubro de 2017, destacou que, no ano de 2016, Minas Gerais foi responsável por 67,69\% do financiamento do custeio da 
cafeicultura com o montante de $\mathrm{R}$ \$ 3,206 bilhões. Minas Gerais continuou sendo o estado que mais contratou financiamento de custeio, representando 70,38\% do montante do crédito, com $\mathrm{R} \$ 2,162$ bilhões. Conforme a SPA/Mapa, três programas oficiais financiaram o crédito agrícola para a cafeicultura nesse período: Programa Nacional de Apoio ao Médio Produtor Rural - PRONAMP, Programa Nacional de Fortalecimento da Agricultura Familiar - PRONAF e Fundo de Defesa da Economia Cafeeira - FUNCAFÉ. O PRONAF foi responsável por 35.121 contratos em 2016 e por 22.045 em 2017; o FUNCAFÉ teve 7.450 contratos celebrados em 2016 e 3.285 em 2017; e o PRONAMP em 2016 foi responsável pela celebração de 7.266 contratos e em 2017 por 4.111 nos nove primeiros meses. E, conforme mencionado, $54 \%$ dos financiamentos foram celebrados 'sem vínculos'.

Uma problemática inserida na produção cafeeira são as relações de trabalho existentes na lavoura, pois grande parte não estão regularizadas. Atualmente o Ministério do Trabalho vem recebendo constantemente denúncias de trabalho associados a escravidão contemporânea em fazendas de café de todo país em especial na mesorregião sul/sudoeste de Minas Gerais.

O Brasil é o maior produtor de café do mundo e mais da metade da safra nacional deriva de Minas Gerais. O Estado gera mais de 3 milhões de empregos diretos e indiretos do setor no país. Ser uma referência mundial em café, coloca o Brasil numa posição de destaque, especialmente em relação aos desafios associados a violações trabalhistas e a direitos humanos em sua cadeia produtiva. Há produtores rurais que convivem há séculos com a cultura da informalidade, alguns da exploração, cooperativas sem mecanismos para impedir situações ilegais e instituições governamentais que não conseguem mudar esse panorama. O Sul de Minas abrange 136 cidades nas regionais do ministério. Dessas, 80 municípios são produtores de café. Considerando cerca de 1 mil trabalhadores por cidade (os dados são incertos pela própria falta de registros), são 80 mil somente na região e desses, $61 \%$ trabalham na informalidade. É o dobro da média que se tem na área urbana. Além de trabalharem sem ter seus direitos trabalhistas resguardados esses trabalhadores muitas das vezes se encontram em alojamento precários, dormem em estábulos e pocilgas; alojamentos multifamiliares (a lei exige que sejam separadas mulheres de homens, ou famílias), falta de sanitários e vestiários, com jornadas longas e exaustivas de trabalho, transporte de trabalhadores precário e falta de equipamentos de segurança nas lavouras.

Segundo a ADERE-MG (Articulação do Empregados Rurais do Estado de Minas Gerais) a informalidade atinge no mínimo 60\% dos trabalhadores nas lavouras de café do Sul de Minas. Ou seja, mais da metade trabalha na colheita do café sem ter carteira assinada. Além de fraudes no pagamento quem tem carteira assinada é vítima de fraude generalizada nas formas de pagamento. $\mathrm{O}$ empregado safrista, durante a colheita do café, trabalha por produção, mas tem registro de pagamento de um salário mínimo, os produtores também não pagam as horas in itineres - que correspondem ao tempo gasto no deslocamento para o local do trabalho e o retorno para o 
alojamento ou para a moradia, os patrões que pagam horas extras são raríssimos. Não é respeitado o período legal ou descanso mínimo de uma hora para a alimentação, como a legislação exige. Na maioria dos casos, são feitas no local de trabalho, onde existem resíduos de agrotóxicos pesados, utilizado de forma intensiva nas lavouras de café sem contar que banheiros químicos e água potável é raridade, faltam equipamentos de proteção individual (EPI) e apenas uma minoria obedece à lei e fornece botina, boné, óculos e máscaras contra os agrotóxicos e gases.

\section{CONSIDERAÇÕES FINAIS}

O desenvolvimento do presente estudo possibilitou uma análise sobre a dinâmica da produção cafeeira na Mesorregião Sul/Sudoeste de Minas Gerais (MSS-MG). Além disso, também permitiu elencar os principais serviços presentes em que são inerentes à cafeicultura, identificando as políticas públicas destinadas ao setor cafeeiro e além disso, possibilitou compreender as particularidades dos estabelecimentos demandantes de mão de obra e os principais problemas relacionados com a precarização do trabalho.

Ao fazer busca de dados quantitativos para o presente artigo evidenciou a dependência econômica da atividade na mesorregião, tanto para a dinâmica urbana quanto agrária, tendo em vista a grande participação de minifúndios e pequenas propriedades como base da produção

Com os dados obtidos sobre produção cafeeira do município de Guaranésia - MG, contatase que este município está entre os produtores do país, trazendo contribuições para a compreensão à cerca realidade histórica e econômica da região.

Perante essa realidade, a análise da conjuntura em que se instituiu dinâmica da produção cafeeira na Mesorregião Sul/Sudoeste de Minas Gerais se faz de extrema importância econômica, histórica, natural e social e poderá contribuir positivamente no avanço de pesquisas futuras.

\section{REFERÊNCIAS}

AGRÍCOLA MUNICIPAL. Levantamento sistemático da produção agrícola (mensal). Disponível em: http://www.ibge.gov.br/home/estatistica/indicadores/agropecuaria. Acesso em: 03 mar. 2019.

ALFREDO, A. Uma abordagem sobre a problemática espaço-temporal no capitalismo contemporâneo. Boletim Mineiro de Geografia, v. 08, n. 13, p. 9-39, 2005.

ANDRADE, R. G. R. A expansão da cafeicultura em Minas Gerais: da intervenção do Estado à liberalização do mercado. 1994. 174 f. Dissertação (Mestrado em Economia) - Faculdade de Ciências Econômicas, Universidade Federal de Minas Gerais, Belo Horizonte, 1994.

ASSOCIAÇÃO BRASILEIRA DA INDÚSTRIA DE CAFÉ - ABIC. Os maiores produtores dos cafés do Brasil. Disponível em: http://abic.com.br/seis-maiores-estados-produtores-dos- cafes-dobrasil-atingiram-98-do-volume-da-safra-de-2017. Acesso em: 03 mar. 2019. 
BRUM, A. J. Modernização da Agricultura: trigo e soja. 1. ed. Petrópolis: Vozes, 1987. 200p

CARLOS, A. F. A. A questão da cidade e do campo: teorias e políticas. Mercator, Fortaleza, v. 3, n. 5, p. 07-13, 2004.

COMPANHIA NACIONAL DE ABASTECIMENTO - CONAB. Produção de Café. Disponível em: $\quad$ https://www.conab.gov.br/ultimas-noticias/2512-producao-de-cafe-deve-ser-a-maior-dahistoria-com-quase-60-milhoes-de-sacas. Acesso em: 03 mar. 2019.

ELIAS, D. Agricultura e produção de espaços urbanos não metropolitanos: notas teóricometodológicas. In: SPOSITO, M. E. B. (Org.). Cidades médias: espaços em transição. São Paulo: Expressão Popular, 2007.

GUILHON, B. “Technologie, Organisation et Performances: Le Cas de la FirmeReseau". Revue d'Economie Politique, p. 46-60, 1992.

INSTITUTO BRASILEIRO DE GEOGRAFIA E ESTATÍSTICA-IBGE. PAM-Produto. Disponível em: https://ibge.gov.br. Acesso em: 03 mar. 2019.

MARX, K. O capital. São Paulo: Abril Cultural, 1984. 396p.

MAZZALI, L. O processo recente de reorganização agroindustrial: do complexo à organização em rede. 1. ed. São Paulo: UNESP, 2007. 170p.

MINISTÉRIO PÚBLICO DO TRABALHO - MPT. Trabalho Escravo. Disponível em: http://portal.mpt.mp.br/wps/portal/portal_mpt/mpt/area-atuacao/trabalho-escravo. Acesso em 18 nov. 2018.

MÜLLER, G. Complexo agroindustrial e modernização agrária. São Paulo: Cebrap, 1985.

OLIVEIRA, A. U. A geografia agrária e as transformações territoriais recentes no campo brasileiro. In: CARLOS, A. F. A. (Org.). Novos caminhos da Geografia. São Paulo: Contexto, 2002. p. 63110.

SAES, A. M.; COSENTINO, D. V.; SILVA, M. P.; GAMBI, T. F. R. Sul de Minas em Transição: ferrovias, bancos e indústrias na constituição do capitalismo na passagem do século XIX para o XX. In: SEMINÁRIO DE ECONOMIA MINEIRA, 14., Diamantina. Anais... Diamantina: CEDEPLAR, 2010. p. 1-20.

SANTOS, M. Técnica, espaço, tempo: globalização e meio técnico científico informacional. São Paulo: Hucitec, 1994. 176p. 